\title{
Increased Exposure of Tissues to Cortisol in Late Pregnancy
}

\author{
C. W. BURKE, ${ }^{*}$ M.A., M.R.C.P. ; F. ROULET. $\dagger$
}

\begin{abstract}
Cummary: In late normal pregnancy the mean $S$ day-night variation of non-protein-bound cortisol in plasma was found to be reduced to $52 \%$, from a mean of $82 \%$ in non-pregnant subjects. Levels of unbound cortisol at midnight and at $9 \mathrm{arm}$. in late pregnancy were raised above the non-pregnant normal. These levels led to increased urinary free cortisol excretion in pregnancy.

This "tissue exposure" in late pregnancy is two to three times normal, as judged by both plasma unbound and urinary free cortisol measurements. The well-known increase in urinary free cortisol excretion in pregnancy is explained by the reduced day-night rhythm.
\end{abstract}

\section{Introduction}

The possibility of increased glucoconticoid activity in pregnancy has interested many workers. It is well known that plasma corticosteroid levels are raised in late pregnancy (Gemzell, 1953; Bayliss et al., 1955). Most of this increase is in the protein-bound fraction because there is a threefold increase in corticosteroid-binding globulin (Doe et al., 1964; De Moor et al., 1966). Since the non-protein-bound fraction is the biologically available moiety for most tissues (Slaunwhite et al., 1962; Matsui and Plager, 1966), it is difficult to draw conclusions from measurements of total corticosteroid levels in pregnancy plasma. It is now accepted that morning levels of unbound plasma cortisol also are increased in late pregnancy (Sandberg et al., 1968; Seal and Doe, 1968). But this increase is slight when compared with the pronounced rise in urinary free cortisol excretion in pregnancy, which often reaches levels seen in Cushing's syndrome (Espiner, 1965; Murphy, 1968). This disproportion is of interest, for it is the unbound fraction of plasma cortisol which is excreted as urinary free cortisol (Beisel et al., 1964). Moreover, the magnitude of cortisol production in late pregnancy is not certain; Cope and Black (1959a) found it was increased, but Migeon et al. (1968) found normal production rates. Thus there is doubt about the prevailing cortisol concentrations to which tissues are exposed in late pregnancy.

We have examined this, using an accurate method to measure the unbound cortisol to which tissue receptors are exposed. The day-night pattern was specially examined, because high night levels of unbound cortisol would readily explain the raised urinary free cortisol excretion in pregnancy, for little cortisol is present at night in normal plasma or urine (Espiner, 1965; Vagnucci et al., 1965). We found that the cortisol changes in late pregnancy showed a remarkable similarity to those of Cushing's syndrome.

\footnotetext{
* Senior Registrar.

† Technician.

Endocrine Unit, Department of Medicine, Royal Postgraduate Medical School, London $\mathrm{W} .12$
}

\section{Subjects and Methods}

Late Pregnancy.-Women admitted to obstetric wards for reasons other than obstetric or endocrine abnormalities or acute intercurrent illness were studied at between 34 and 38 weeks' gestation. Blood was drawn at midnight and 9 a.m. during a 24-hour urine collection.

Normal Subjects.-Healthy volunteers from hospital staff were studied. Urine collections were also made from a number of hospital inpatients without endocrine disease or stressful illness.

Cushing's Syndrome.-Ten cases of Cushing's disease, shown to be "pituitary-dependent" by plasma and urinary steroid measurements under basal conditions and during motyrapone and dexamethasone administration, were similarly studied. Eight were known to have pituitary tumours; two have since died of the disease.

Unbound contisol in plasma was measured by steady-state gel filtration as previously described (Burke, 1969a). The coefficient of variation of replicate estimates by this method was $3.5 \%$.

Uninary free (unconjugated) and total plasma cortisol were measured by competitive protein-binding analysis of dichloromethane extracts (Beardwell et al., 1968). Progesterone, which interferes with this method, was removed from urines by preliminary petroleum ether washing; this made no difference to results in plasma. The three natural and several synthetic oestrogens were shown not to interfere with the assay (see also Murphy, 1967).

\section{Results}

Unbound cortisol levels are approximately log-normally distributed (Burke, 1969b) as is urinary free cortisol excretion (as judged by the figures of Cope and Black, 1959b). Statistical comparisons were therefore made on logarithmic values (Gaddum, 1945) and Figs. 1, 2, and 4 are drawn with logarithmic scales. The means and S.D. depicted are derived from the log values.

Midnight Levels of Unbound Cortisol.-Midnight levels of unbound cortisol in late pregnancy are increased above those found in normal subjects $(\mathrm{P}<0.001)$ and approach values found in some cases of Cushing's syndrome (Fig. 1). There is no significant overlap with the normal range. (Two cases of Cushing's syndrome were studied twice.)

Unbound Cortisol at 9 a.m.-Unbound cortisol levels at 9 a.m. in late pregnancy are higher than those in non-pregnant women $(P<0.001)$ (Fig. 2). Though the levels at this time of day are as high as in some cases of Cushing's syndrome there is an overlap with the normal range. These values for unbound cortisol at 9 a.m. are similar to those found by other workers quoted above.

Day-night rhythm.-The ,hanges in unbound cortisol are 


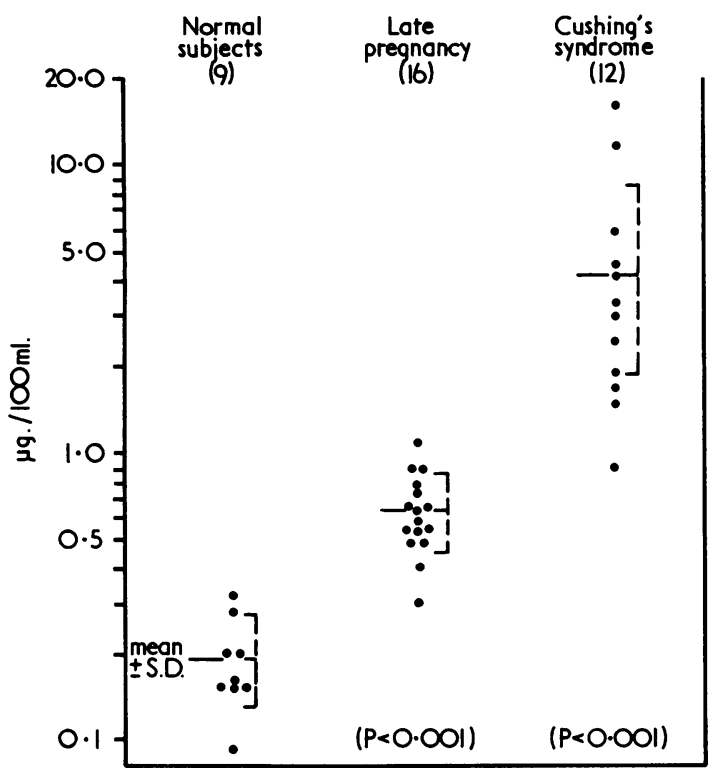

FIG. 1.-Plasma unbound cortisol levels at midnight (10 g. mean shown).

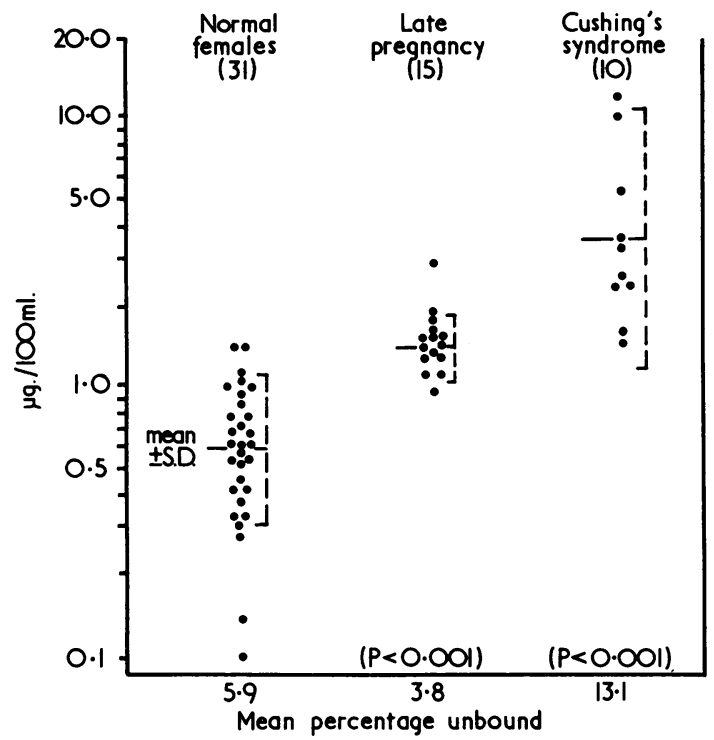

Fig. 2.-Plasma unbound cortisol levels at 9 a.m.

summarized in Fig. 3, which shows the day-night variation. For each subject the midnight unbound cortisol level was expressed as a percentage of the 9 a.m. level, and the mean ( \pm S.D.) percentage is shown for each group. It can be seen that the normal mean day-night variation (82\%) is much reduced in late pregnancy (to $52 \%, \mathrm{P}<0.001$ ). The day-night rhythm is not, however, completely abolished, as it is in Cushing's syndrome.

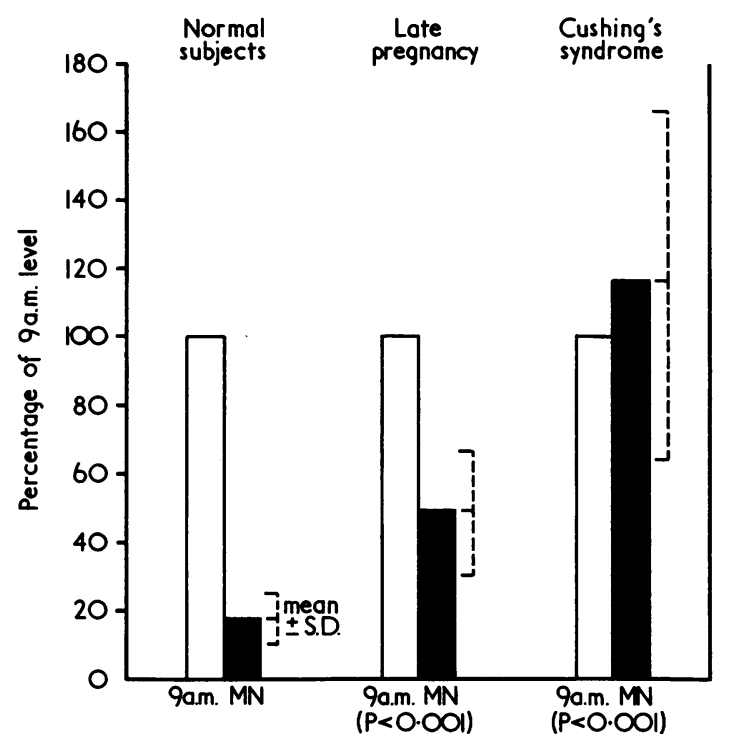

FIG. 3.-Day-night variation of plasma unbound cortisol (9 a.m. and midnight).

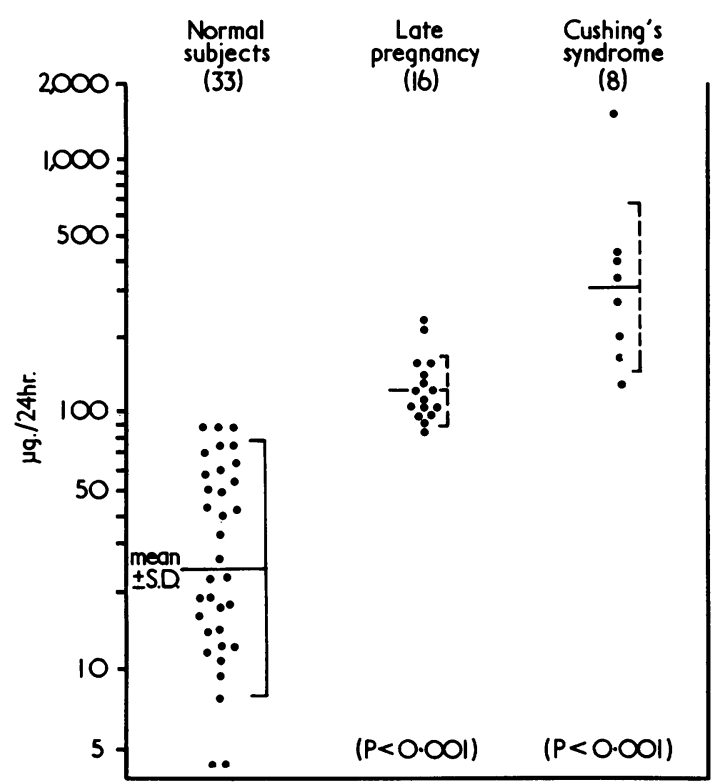

FIG. 4.-Daily urinary free cortisol excretion.

Urinary Free Cortisol.-The much-increased urinary free cortisol excretion in late pregnancy $(P<0.001)$ approaches values found in Cushing's syndrome (Fig. 4). There is little overlap with the normal range, in conformity with the high midnight levels.

The range of values for all these measurements, with the arithmetic means, is shown in the Table.

\begin{tabular}{|c|c|c|c|c|c|c|c|c|}
\hline \multirow[t]{2}{*}{ Group } & \multicolumn{2}{|c|}{$\begin{array}{l}9 \text { a.m. Total Plasma } \\
\text { Cortisol ( } \mu \mathrm{g} . / 100 \mathrm{ml} .)\end{array}$} & \multicolumn{2}{|c|}{$\begin{array}{l}9 \text { a.m. Unbound Plasma } \\
\text { Cortisol ( } \mu \mathrm{g} . / 100 \mathrm{ml} .)\end{array}$} & \multicolumn{2}{|c|}{$\begin{array}{l}\text { Midnight Unbound Plasma } \\
\text { Cortisol ( } \mu \mathrm{g} . / 100 \mathrm{ml} .)\end{array}$} & \multicolumn{2}{|c|}{ 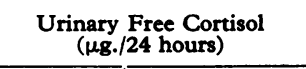 } \\
\hline & Mean* & Range & Mean* & Range & Mean* & Range & Mean ${ }^{*}$ & Range \\
\hline $\begin{array}{l}\text { Normal women } \\
\text { Late pregnancy } \\
\text { Cushing's syndrome }\end{array}$ & $\begin{array}{l}12 \cdot 0 \\
38 \cdot 1 \\
30 \cdot 6\end{array}$ & 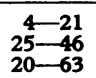 & $\begin{array}{l}0.66 \\
1.41 \\
4.03\end{array}$ & $\begin{array}{l}0.1-1.8 \\
0.9-2.8 \\
1.5-11.2\end{array}$ & $\begin{array}{l}0.18 \\
0.64 \\
5.57\end{array}$ & $\begin{array}{l}0-0.32 \\
0.3-1.1 \\
0.9-17.0\end{array}$ & $\begin{array}{r}39 \\
129 \\
417\end{array}$ & $\begin{array}{c}0-98 \\
85-252 \\
125-1,410\end{array}$ \\
\hline
\end{tabular}

*Arithmeric mean 


\section{Discussion}

A preliminary account of this work was given earlier (Burke, 1969c). During the preparation of this paper Doe et al. (1969) reported similar rises of unbound cortisol in blood drawn at 9 a.m. and 9 p.m. in late pregnancy, using different analytical methods. We believe it advantageous to study night plasma levels at midnight rather than 9 p.m., for in some subjects minimum levels are not reached before 10 or 11 p.m. Doe et al. do not give figures for urinary cortisol; our results confirm and add to their findings by showing that both plasma and urinary cortisol concentrations in late pregnancy are increased throughout the 24 hours. Our results and those of Doe et al. leave little room for doubt that the day-night variation of unbound cortisol is much diminished in late pregnancy. The reduced day-night rhythm of urinary free cortisol shown by Espiner (1965) is thus explained.

The control of the day-night rhythm of plasma cortisol resides in the hypothalamus, as does the feedback control mechanism for corticotrophin and hence plasma cortisol. This feedback mechanism appears to respond to unbound rather than total cortisol (Kawai and Yates, 1966). Therefore the presence of increased unbound cortisol with disturbed day-night rhythm in late pregnancy implies alteration of the maternal hypothalamic control of cortisol production.

This is true whatever the source of the circulating cortisol. Even if cortisol were introduced from outside the maternal circulation-for example, by the fetus or placenta-intact maternal hypothalamic control would reset maternal corticotrophin, and hence unbound cortisol levels, unless the amount of cortisol introduced exceeded maternal production. It does not seem likely that so much cortisol is produced by the fetoplacental unit (Cope, 1964). It is more probable that the high circulating cortisol levels in pregnancy are of maternal origin.

The cause of the alteration in maternal control is uncertain. Oestrogen administration increases unbound cortisol levels (Burke, 1969b), and it is possible that some of the changes occurring in late pregnancy are due to high prevailing oestrogen levels. There must be other factors, however, since the disturbance of day-night cortisol rhythm associated with even highdose oestrogen administration is less than that found in pregnancy (Doe et al., 1969). Evidently further research into the final causes of these changes is required.

It is of interest that the long-known increase in urinary free cortisol excretion in late pregnancy does reflect increased plasma unbound cortisol. In effect the kidney performs an integration of plasma unbound cortisol with respect to time, the area under the plasma diurnal curve being manifested as urinary free cortisol excretion. This area under the curve is a measure of the "tissue exposure" (concentration $\times$ time) to unbound cortisol.

Many workers have sought evidence of increased cortisol levels in pregnancy to explain phenomena such as striae gravidarum, impairment of carbohydrate tolerance, hypertension, fluid retention, and amelioration of inflammatory processes such as arthritis. The present findings provide clear evidence of increased and sustained exposure of tissues to cortisol in late pregnancy. The changes in the third trimester are sufficiently pronounced to resemble a form of self-limited Cushing's syndrome. For example, in late pregnancy the mean plasma unbound cortisol was $1.41 \mu \mathrm{g} . / 100 \mathrm{ml}$. at 9 a.m. and $0.64 \mu \mathrm{g}$. at midnight-a daily average of $1.0 \mu \mathrm{g}$; whereas in the normal subjects the mean fell from $0.66 \mu \mathrm{g}$. at 9 a.m. to $0.18 \mu \mathrm{g}$. at midnight, giving a daily average of $0.4 \mu \mathrm{g}$. Thus maternal tissues are exposed to an average daily concentration of unbound cortisol two and a half times normal. This degree of tissue exposure would occur in a mild case of Cushing's syndrome having a plasma true cortisol at morning and night of no more than $15 \mu \mathrm{g} . / 100 \mathrm{ml}$. (or about $22 \mu \mathrm{g} . / 100 \mathrm{ml}$. of 11 -hydroxycorticosteroids), assuming normal corticosteroid-binding globulin levels.

Many other hormonal changes occur in late pregnancy-for example, the presence of placental lactogen which has some metabolic effects in common with cortisol (Samaan et al., 1968). It is therefore not correct to assume that clinical features common to pregnancy and Cushing's syndrome are necessarily due entirely to cortisol excess; but raised cortisol levels are probably an important factor in their generation.

This work was made possible by the co-operation of the subjects and by the willing help given by the house-physicians and nursing staff of the obstetric department. We are grateful to Professor J. C. McClure Browne, Mr. H. C. Gordon, Mr. D. Hawkins and Professor T. Russell Fraser for permission to study patients under their care. The work was carried out during the tenure of Medical Research Council grants to Professor T. Russell Fraser. We are much indebted to Dr. C. L. Cope for continued encouragement.

REFERENCES

Bayliss, R. I. S., Browne, J. C. McC., Round, B. P., and Steinbeck, A. W. (1955). Lancet, 1, 62

Beardwell, C. G., Burke, C. W., and Cope, C. L. (1968). Fournal of Endocrinology, 42, 79.

Beisel, W. R., Cos, J. J., Horton, R., Chao, P. Y., and Forsham, P. H. (1964). Fournal of Clinical Endocrinology and Metabolism, 24, 887 Burke, C. W. (1969a). Biochimica et Biophysica Acta, 176, 403.

Burke, C. W. (1969a). Biochimica et Biophysica Acta, 176,
Burke, C. W. (1969b). British Medical fournal, 2, 798.

Burke, C. W. (1969b). British Medical fournal, 2, 798. 138 , p. 58.

Cope, C. L. (1964). Adrenal Steroids and Disease, p. 757. London, Pitman.

Cope, C. L., and Black, E. G. (1959a). fournal of Obstetrics and Gynaecology of the British Empire, 66, 404.

Cope, C. L., and Black, E. G. (1959b). British Medical fournal, 2, 1117 .

De Moor. P., Steeno, O., Brosens, I., and Hendrikx, A. (1966). Fournal of Clinical Endocrinology and Metabolism, 26, 71

Doe, R. P. Dickinson, P., Zinneman, H. H. and Seal, U. S. (1969). fournal of Clinical Endocrinology and Metabolism, 29, 757.

Doe, R. P., Fernandez, R., and Seal, U. S. (1964). Fournal of Clinical Endocrinology and Metabolism, 24, 1029.

Espiner, E. A (1965). Fournal of Endocrinology, 35, 29.

Espiner, E. A. (1965). Fournal of Endocrinc

Gaddum, J. H. (1945). Nature, 156. 463 . lism, 13, 898 .

Kawai, A., and Yates, F. E. (1966). Endocrinology, 79, 1040.

Matsui, N., and Plager, J. E. (1966). Endocrinology, 78, 1159.

Migeon, C. J., Kenny, F. M., and Taylor, F. H. (1968). Fournal of Clinical Endocrinology and Metabolism, 28, 661 .

Murphy, B. E. P. (1967). Fournal of Clinical Endocrinology and Metabolism, 27.973.

Murphy, B. E. P. (1968). Fournal of Clinical Endocrinology and Metabolism, 28, 343.

Samaan, N., Yen, C. C., Gonzalez, D., and Pearson, O. H. (1968) fournal of Clinical Endocrinology and Metabolism, 28, 485.

Sandberg A. A., Rosenthal, H. H., and Slaunwhite, W. R. (1968). Excerpta Medica Foundation International Congress Series. No. 157, cerpta Medica Foundation

Seal, U. S.. and Doe, R. P. (1968). Excerpta Medica Foundation International Congress Series. No. 157, abstract No. 403, p. 161.

Slaunwhite, W. R., Lockie, G. N., Back, N., and Sandberg, A. A. (1962) Science, 135, 1062.

Vagnucci, A. I., et al. (1965). Fournal of Clinical Endocrinology and Metabolism, 25, 1331 